\title{
The tangible consequences and intangible implications of laparoscopic cholecystectomy- associated bile duct injuries
}

\author{
J Lindemann, ${ }^{1,2}$ (D) J Krige, ${ }^{1}$ (D) E Jonas ${ }^{1}$ (D) \\ ${ }^{1}$ Surgical Gastroenterology Unit, Department of Surgery, Faculty of Health Sciences, Groote Schuur Hospital, University of Cape Town, \\ South Africa \\ ${ }^{2}$ Department of Surgery, Washington University School of Medicine, United States of America
}

Corresponding author, email: lindemann.jessica@gmail.com

When laparoscopic cholecystectomy (LC) was introduced more than two decades ago, alarming rates of bile duct injuries (BDIs) occurred in up to $0.4 \%$ of operations, twice as often as with open cholecystectomy, with only a recent decrease in incidence. ${ }^{1}$ Three contemporary studies from the National Health Service database in the UK and two statewide databases in the USA (New York and California), report laparoscopic cholecystectomy bile duct injury (LC-BDI) rates between $0.08-0.22 \%$, which are comparable to open cholecystectomy, but these estimations may not accurately represent the true incidence of BDIs elsewhere. ${ }^{2-4}$

While minor partial injuries with duct continuity can be treated successfully with endoscopic stenting without recourse to operation, major injuries with duct division are potentially life-threatening and may require complex biliary reconstructive surgery. ${ }^{5}$ Correct initial management is crucial as undue treatment delay and inappropriate initial intervention may result in serious early complications, including biliary peritonitis and multi-organ failure. ${ }^{6}$ Suboptimal surgical management may lead to recurrent ascending cholangitis, secondary biliary cirrhosis and portal hypertension. ${ }^{7}$ Patients who underwent BDI repair have a substantially decreased survival rate with a four-fold increased long-term risk of dying prematurely from liver disease compared with the general population. ${ }^{8}$ Optimal evaluation of a major BDI therefore requires a coordinated multidisciplinary assessment by experienced surgeons, endoscopists and interventional radiologists. ${ }^{9-11}$ Reparative biliary surgery is technically demanding and should be undertaken only by a surgical team with expertise and established credentials. ${ }^{12-14}$ Centralisation of cases in high volume centres with surgeons committed to and interested in the management of this complication shows improvement in early and long-term results. ${ }^{12,15}$

Both the tangible consequences and the covert intangible implications of a major BDI can be profound, with the spectre of protracted hospitalisation and invasive investigations, the anxiety of major reconstructive surgery, a lengthy rehabilitation period, loss of income, and in some cases prolonged and unpleasant litigation, all of which may result in a significant decrease in health-related quality of life (HRQoL). ${ }^{16,17}$ While the medico-legal issues are often reported and frequently sensationalised in the media, there has been less focus on the socioeconomic impact, in particular from the patient's perspective. In the worst-case scenario, a patient may face financial ruin with severe repercussions, especially where he or she is the sole breadwinner for an extended family.

The financial consequences can be substantial for the healthcare provider, the injuring surgeon, malpractice insurance companies and, not least, the patient. An analysis of the available information on costs, including studies from the USA, Belgium and India, emphasises that the total cost of BDI repair is considerably greater than an uncomplicated LC and the quantum increases with delayed recognition of the injury and with an inadequate repair by the injuring surgeon. ${ }^{18}$ Savader et al. in 1997 reported that the mean cost of a definitive bile duct reconstruction was US \$51 $411\left(\mathrm{R} 731845^{*}\right)$ and ranged from 4.5 to 26 times the cost of an uncomplicated LC. ${ }^{19}$ South African data on the cost implications of a LC-BDI are limited. In a Cape Town study from 2015, total mean cost with adjustment for inflation in a cohort of 44 patients with a major BDI repaired by Rouxen-Y hepaticojejunostomy, was R215 711 which is 6.4 times the cost of an uncomplicated LC and the most expensive repair amounted to R980 830 after 86 days in hospital. ${ }^{20}$ Accumulated costs before referral may also be substantial, including imaging, intervention for complications and an unsuccessful initial attempt at a definitive repair of the injury. Importantly, no studies have accounted for costs of management before referral. ${ }^{19,20}$

Whereas there are data on the costs incurred for the healthcare provider and the magnitude of financial settlements by the injuring surgeon and/or insurance companies as has been shown, there is little in-depth information from the patients' perspective. An aspect frequently overlooked is the paucity of data on the indirect and personal costs incurred by the patient after a BDI. These include diverse costs such as loss of income due to time off work, travel expenses, medical fees, rehabilitation and litigation. Loss of income may also extend to a partner or spouse involved in a supportive capacity who may need to travel long distances between home and the hospital where the repair is done. ${ }^{20}$ In a worstcase scenario inability to return to his or her profession may result in permanent loss of income. 
The threat of litigation looms large in complications following laparoscopic surgery. In no other surgical field has the growth of litigation been as rapid as in LC and one-third of general surgery indemnity (money paid out by insurers) arises from laparoscopic procedures. ${ }^{21}$ The vulnerability of BDIs to civil litigation is well known to the plaintiff and in medical malpractice litigation, biliary injury ranks first on the list of negligence claims worthy of pursuance. Four studies from the United States by Chandler, Kern, McLean and Carroll have examined litigation following LC. ${ }^{22-25}$ Among these, McLean in 2006, reported an average payment of \$508 341 (R7 236 335*) in 104 patients where complications followed LC. ${ }^{24}$ In England data from the National Health Service Litigation Authority on clinical negligence claims following LC showed that 418 claims were made in 2006, of which 303 were settled, two-thirds in the claimant's favour. ${ }^{26}$ The average payout for a successful claim was $£ 102827$ (R1 $\left.916076^{*}\right) .{ }^{26}$ However, the application and outcome of medical malpractice litigation varies considerably worldwide. For example, the system in the Netherlands differs from the litigation and tort system used in the US. Dutch malpractice litigation is conducted through an arbitration system, which is common in several European countries. There are no jury trials, there is no contingency system, and large settlements are less common with a mean financial settlement of $€ 12795$ (R202 216*) for BDI reported in $2008 .{ }^{27}$ In addition, the associated mea culpa concerns and moral liability as well as the consequences of litigation may have a detrimental effect on the injuring surgeon's life and psyche. Concerns regarding possible reputational damage to the surgeon's practice may be further compounded by angst, loss of confidence, uncomplimentary media coverage and protracted litigation. Ultimately, both parties, the patient and the surgeon, may become victims as two opposing legal teams quibble, spar and joust for pecuniary advantage and a favourable verdict.

Health-related QoL, a cumulative consequence of the above factors has also received considerably less attention. While there are numerous publications on BDIs, only 12 have investigated HRQoL after BDI. ${ }^{16,28-38}$ Assessing HRQoL is important and relevant as this quantifies the impact and consequences of a BDI from the patient's perspective, reflects self-perception of well-being and considers functionality or relief of a particular symptom, emotional status, social role, and mental health. ${ }^{39}$ Previous studies on HRQoL outcome after BDI have reported discordant results, with some showing no difference between LC-BDI patients and those who had an uneventful LC, while others report significant long-term reductions in both physical and mental HRQoL. ${ }^{40}$ This discordance may be due to underpowered designs, sample selection, selection bias and inclusion of heterogeneous populations treated with either endoscopy, interventional radiology or surgery. ${ }^{31}$ In the first detailed analysis of the impact of LC-BDI on HRQoL, the Amsterdam group used the Short Form 36 Health Survey ${ }^{\circledR}$ (SF-36) and reported worse physical and mental HRQoL compared to an uncomplicated LC cohort and average general population values. ${ }^{30}$ These findings were later replicated in an expanded sample by the same group and were similar to a report from Moore et al., showing worse SF-36 physical and mental HRQoL in BDI patients compared with LC patients. ${ }^{16,36}$ However, in a study that used the modified City of Hope
HRQoL assessment tool, Melton et al. reported worse mental HRQoL in BDI patients but no effect of BDI on physical and social HRQoL, compared with a healthy cohort. ${ }^{35}$ This is in contrast to a report by Sarmiento et al. which reported no difference in HRQoL after a minimum of five years followup between BDI repair patients and those undergoing an uncomplicated LC. ${ }^{27}$ Similarly, Hogan et al. concluded that the HRQoL of patients after BDI repair compares favourably with that of an uncomplicated LC. ${ }^{34,38}$

Two systematic reviews, one published in 2013 by Landman et al. and another currently in press by HalleSmith and colleagues concluded that given the current available evidence, it is difficult to make any conclusions about the influence of BDI on HRQoL. ${ }^{40,41}$ The Landman paper, after controlling for length of follow-up, found there was no difference between matched BDI and uneventful LC patients in the physical composite HRQoL score. ${ }^{40}$ However, BDI patients were 38 times more likely to have a decreased mental composite score and this reduced score did not seem to improve over time. Halle-Smith et al. concluded that the effect of BDI on HRQoL remains unclear, but that it is possibly related to the severity of the injury and whether a surgical repair was performed, a conclusion that seems plausible despite several studies that conclude the contrary. ${ }^{41}$

There are several factors that can be attributed to the absence of analyses of large patient cohorts in the form of meta-analyses, that make comprehensive investigation challenging for this important and relevant topic. No diseasespecific HRQoL survey tool for patients with BDI exists, and although the SF-36 and Gastrointestinal QoL (GiQLi) surveys are the most commonly used, there is a significant degree of variability in HRQoL surveys used between studies. In addition to defining a suitable reference group, timing of survey administration could influence HRQoL scores and should be considered in the interpretation of results. Finally, as BDI is a rare event, patients with all types of BDIs are often included in HRQoL studies which results in comparison of HRQoL for patients with minor bile leaks that resolve with conservative management to patients with major BDIs requiring surgical repair. The relationship between litigation and HRQoL after BDI is also important to consider. In two HRQoL studies that included litigation as a factor potentially influencing HRQoL, litigation was found to have a negative impact on HRQoL scores compared to BDI patients who did not pursue litigation, uneventful LC and healthy population controls. ${ }^{35,36}$ Melton et al. have shown that patients with a BDI who are involved in legal proceedings have a poorer quality of life. ${ }^{35}$ In the largest study to date, including $800 \mathrm{BDI}$ patients, the Amsterdam group reported a significant reduction in HRQoL in patients involved in malpractice litigation, but interestingly significantly better HRQoL when the verdict of the malpractice claim was in the patient's favour than when it was not. ${ }^{16}$

In conclusion, early recognition of a BDI and referral to a hepatobiliary surgeon are essential to reduce morbidity and ensure a satisfactory surgical outcome. ${ }^{11}$ The findings in the Cape Town study, where the BDIs in more than half of the patients were only recognised after five days and in three quarters presented with sepsis due to cholangitis or biliary peritonitis, reinforce the maxim that all LC patients who have any deviation from the expected postoperative course, notably postoperative abdominal symptoms, require

* Is based on the January 2020 current exchange rates for currency conversion to South African Rand. 
thorough assessment and investigation to exclude an iatrogenic BDI. ${ }^{20}$ Analysis shows that socio-economic and litigation implications of a major BDI incurred during LC remains a serious concern for patients, healthcare providers and employers and is associated with long-term HRQoL impairment as well as increased costs that may impact years after surgery. The ensuing consequences may lead to litigation which results in a substantial financial drain on the healthcare and insurance systems. In order to minimise these unfortunate and preventable consequences in future, it behoves surgeons to make a BDI after LC a rare event.

\section{Conflict of interest}

The authors have no conflicts of interest to declare.

\section{Funding source}

None.

\section{Ethics approval}

Waved for editorial manuscript.

\section{Plagiarism}

This work has not been previously presented or published and is not currently under review.

\section{ORICD:}

J Lindemann (D) https://orcid.org/0000-0002-8089-0191

J Krige (D) https://orcid.org/0000-0002-7057-9156

E Jonas (iD https://orcid.org/0000-0003-0123-256X

\section{REFERENCES}

1. Martin D, Uldry E, Demartines N, Halkic N. Bile duct injuries after laparoscopic cholecystectomy: 11-year experience in a tertiary center. Biosci Trends. 2016;10(3):197-201. https:// doi.org/10.5582/bst.2016.01065. PMID: 27319974.

2. Fong ZV, Pitt HA, Strasberg SM, et al. Diminished survival in patients with bile leak and ductal injury: management strategy and outcomes. J Am Coll Surg. 2018;226(4):568-76. https://doi.org/10.1016/j.jamcollsurg.2017.12.023. PMCID: PMC6053912.

3. Halbert C, Pagkratis S, Yang J, et al. Beyond the learning curve: incidence of bile duct injuries following laparoscopic cholecystectomy normalize to open in the modern era. Surg Endosc. 2016;30(6):2239-43. https://doi.org/10.1007/s00464015-4485-2. PMID: 26335071.

4. El-Dhuwaib Y, Slavin J, Corless DJ, et al. Bile duct reconstruction following laparoscopic cholecystectomy in England. Surg Endosc. 2016;30(8):3516-25. https://doi. org/10.1007/s00464-015-4641-8. PMCID: PMC4956705.

5. Nordin A, Halme L, Makisalo H, Isoniemi H, Hockerstedt K. Management and outcome of major bile duct injuries after laparoscopic cholecystectomy: from therapeutic endoscopy to liver transplantation. Liver Transpl. 2002;8(11):1036-43. https://doi.org/10.1053/jlts.2002.35557. PMID: 12424717.

6. Krige JE, Bornman PC, Kahn D. Bile leaks and sepsis: drain now, fix later. Arch Surg. 2010;145(8):763. https://doi. org/10.1001/archsurg.2010.154. PMID: 20737735.

7. Rauws EA, Gouma DJ. Endoscopic and surgical management of bile duct injury after laparoscopic cholecystectomy. Gastroenterol. 2004;18(5):829-46. https://doi.org/10.1016/j. bpg.2004.05.003. PMID: 15494281.
8. Tornqvist B, Zheng Z, Ye W, Waage A, Nilsson M. Long-term effects of iatrogenic bile duct injury during cholecystectomy. Clin Gastroenterol Hepatol. 2009;7(9):1013-8. https://doi.org 10.1016/j.cgh.2009.05.014. PMID: 19465151.

9. De Reuver PR, Rauws EA, Bruno MJ, et al. Survival in bile duct injury patients after laparoscopic cholecystectomy: a multidisciplinary approach of gastroenterologists, radiologists, and surgeons. Surgery. 2007;142(1):1-9. https://doi.org/ 10.1016/j.surg.2007.03.004. PMID: 17629994.

10. Nuzzo G, Giuliante F, Giovannini I, et al. Advantages of multidisciplinary management of bile duct injuries occurring during cholecystectomy. Am J Surg. 2008;195(6):7639. https://doi.org/10.1016/j.amjsurg.2007.05.046. PMID: 18367147.

11. Krige JE, Jonas E, Hofmeyr S. Instilling a culture of safety for laparoscopic cholecystectomy. S Afr J Surg. 2016;54(3):2-5. PMID: 28240459.

12. $\mathrm{Xu} \mathrm{XD}$, Zhang YC, Gao $\mathrm{P}$, et al. Treatment of major laparoscopic bile duct injury: a long-term follow-up result. Am Surg. 2011;77(12):1584-8. PMID: 22273213.

13. De Reuver PR, Grossmann I, Busch OR, et al. Referral pattern and timing of repair are risk factors for complications after reconstructive surgery for bile duct injury. Ann Surg. 2007;245(5):763-70. https://doi.org/10.1097/01. sla.0000252442.91839.44. PMCID: PMC1877064.

14. Terblanche J, Worthley CS, Spence RA, Krige JE. High or low hepaticojejunostomy for bile duct strictures? Surgery. 1990;108(5):828-34. PMID: 2237762.

15. Perera MT, Silva MA, Hegab B, et al. Specialist early and immediate repair of post-laparoscopic cholecystectomy bile duct injuries is associated with an improved longterm outcome. Ann Surg. 2011;253(3):553-60. https://doi. org/10.1097/SLA.0b013e318208fad3. PMID: 21217507.

16. Booij KAC, De Reuver PR, Van Dieren S, et al. Long-term impact of bile duct injury on morbidity, mortality, quality of life, and work related limitations. Ann Surg. 2018;268(1):14350. https://doi.org/10.1097/SLA.0000000000002258. PMID: 28426479.

17. Hartnett DA, Eltorai AEM, Osband AJ, Ahmed SA, Daniels AH. Cholecystectomy-related malpractice litigation: predictive factors of case outcome. Updates Surg. 2019;71(3):463469. https://doi.org/10.1007/s13304-019-00633-4. PMID: 30783959 .

18. Krige JE, Lindemann J, Jonas E. Socio-economic and medicolegal issues related to bile duct injury. Comment in: Kapoor, VK, eds. Post-cholecystectomy Bile Duct Injury. Springer Singapore; 2020.

19. Savader SJ, Lillemoe KD, Prescott CA, et al. Laparoscopic cholecystectomy-related bile duct injuries: a health and financial disaster. Ann Surg. 1997;225(3):268-73. https:// doi.org/10.1097/00000658-199703000-00005. PMCID: PMC1190676.

20. Hofmeyr S, Krige JE, Bornman PC, Beningfield SJ. A cost analysis of operative repair of major laparoscopic bile duct injuries. S Afr J Surg. 2015;105(6):454-7. https://doi. org/10.7196/samj.9038. PMID: 26716161.

21. Flum DR, Dellinger EP, Cheadle A, Chan L, Koepsell T. Intraoperative cholangiography and risk of common bile duct injury during cholecystectomy. JAMA. 2003;289(13):163944. https://doi.org/10.1001/jama.289.13.1639. PMID: 12672731 .

22. Chandler JG, Voyles CR, Floore TL, Bartholomew LA. Litigious consequences of open and laparoscopic biliary 
surgical mishaps. J Gastrointest Surg. 1997;1(2):138-45. https://doi.org/10.1016/s1091-255x(97)80101-1. PMID: 9834340.

23. Kern KA. Malpractice litigation involving laparoscopic cholecystectomy. Cost, cause, and consequences. Arch Surg. 1997;132(4):392-8. https://doi.org/10.1001/archsurg.1997. 01430280066009. PMID: 9108760.

24. McLean TR. Risk management observations from litigation involving laparoscopic cholecystectomy. Arch Surg. 2006;141(7):643-8. https://doi.org/10.1001/archsurg.141.7. 643. PMID: 16847233.

25. Carroll BJ, Birth M, Phillips EH. Common bile duct injuries during laparoscopic cholecystectomy that result in litigation. Surg Endosc. 1998;12(4):310-4. https://doi.org/10.1007/ s004649900660. PMID: 9543519.

26. Alkhaffaf B, Decadt B. 15 years of litigation following laparoscopic cholecystectomy in England. Ann Surg. 2010;251 (4):682-5. https://doi.org/10.1097/SLA.0b013e3181cc99fd. PMID: 20224377.

27. De Reuver PR, Wind J, Cremers JE, et al. Litigation after laparoscopic cholecystectomy: an evaluation of the Dutch arbitration system for medical malpractice. J Am Coll Surg. 2008;206(2):328-34. https://doi.org/10.1016/j. jamcollsurg.2007.08.004. PMID: 18222388 .

28. AbdelRafee A, El-Shobari M, Askar W, Sultan AM, El Nakeeb A. Long-term follow-up of 120 patients after hepaticojejunostomy for treatment of post-cholecystectomy bile duct injuries: A retrospective cohort study. Int J Surg. 2015;18:205-10. https://doi.org/10.1016/j.ijsu.2015.05.004. PMID: 25965917.

29. Boerma D, Rauws EA, Keulemans YC, et al. Impaired quality of life 5 years after bile duct injury during laparoscopic cholecystectomy: a prospective analysis. Ann Surg. 2001;234(6):750-7. https://doi.org/10.1097/00000658200112000-00006. PMCID: PMC1422134.

30. De Reuver PR, Sprangers MA, Rauws EA, et al. Impact of bile duct injury after laparoscopic cholecystectomy on quality of life: a longitudinal study after multidisciplinary treatment. Endoscopy. 2008;40(8):637-43. https://doi. org/10.1055/s-2008-1077444. PMID: 18680076.

31. Dominguez-Rosado I, Mercado MA, Kauffman C, et al. Quality of life in bile duct injury: 1-, 5-, and 10-year outcomes after surgical repair. J Gastrointest Surg. 2014;18(12):208994. https://doi.org/10.1007/s11605-014-2671-5. PMID: 25305036 .
32. Ejaz A, Spolverato G, Kim Y, et al. Long-term health-related quality of life after iatrogenic bile duct injury repair. J Am Coll Surg. 2014;219(5):923-32 e10. https://doi/org/10.1016/j. jamcollsurg.2014.04.024. PMID: 25127511.

33. Flores-Rangel GA, Chapa-Azuela O, Rosales AJ, RocaVasquez C, Bohm-Gonzalez ST. Quality of life in patients with background of iatrogenic bile duct injury. World J Surg. 2018;42(9):2987-91. https://doi.org/10.1007/s00268-0184564-3. PMID: 29520485.

34. Hogan AM, Hoti E, Winter DC, et al. Quality of life after iatrogenic bile duct injury: a case control study. Ann Surg. 2009;249(2):292-5. https://doi.org/10.1097/ SLA.0b013e318195c50c. PMID: 19212184.

35. Melton GB, Lillemoe KD, Cameron JL, et al. Major bile duct injuries associated with laparoscopic cholecystectomy: effect of surgical repair on quality of life. Ann Surg. 2002;235 (6):888-95. https:/doi.org/10.1097/00000658-20020600000018. PMCID: PMC1422520.

36. Moore DE, Feurer ID, Holzman MD, et al. Long-term detrimental effect of bile duct injury on health-related quality of life. Arch Surg. 2004;139(5):476-82. https://doi org/10.1001/archsurg. 139.5.476. PMID: 15136346.

37. Rystedt JM, Montgomery AK. Quality-of-life after bile duct injury: intraoperative detection is crucial. A national casecontrol study. HPB (Oxford). 2016;18(12):1010-6. https://doi org/10.1016/j.hpb.2016.09.003. PMCID: PMC5144547.

38. Sarmiento JM, Farnell MB, Nagorney DM, Hodge DO, Harrington JR. Quality-of-life assessment of surgical reconstruction after laparoscopic cholecystectomy-induced bile duct injuries: what happens at 5 years and beyond? Arch Surg. 2004;139(5):483-9. https://doi.org/10.1001/ archsurg.139.5.483. PMID: 15136347.

39. Velanovich V. Using quality-of-life measurements in clinical practice. Surgery. 2007;141(2):127-33. https://doi org/10.1016/j.surg.2006.10.002. PMID: 17263966.

40. Landman MP, Feurer ID, Moore DE, Zaydfudim V, Pinson $\mathrm{CW}$. The long-term effect of bile duct injuries on healthrelated quality of life: a meta-analysis. HPB (Oxford). 2013;15(4):252-9. https://doi.org/10.1111/j.1477-2574.2012. 00586.x. PMCID: PMC3608978.

41. Halle-Smith JM, Hodson J, Stevens LG, et al. A comprehensive evaluation of the long-term economic impact of major bile duct injury. HPB (Oxford). 2019;21(10):1312-1321. https:// doi.org/10.1016/j.hpb.2019.01.018. PMID: 30862441. 